\title{
Isolated and concomitant minimally invasive minithoracotomy aortic valve surgery
}

\author{
Joseph Lamelas, MD, ${ }^{\text {a,b,c }}$ Maurice Mawad, MD, ${ }^{a}$ Roy Williams, MD, ${ }^{\text {a }}$ Ursula Keller Weiss, PhD, ${ }^{\text {a }}$ \\ Qianzi Zhang, MPH, ${ }^{\mathrm{d}}$ and Angelo LaPietra, $\mathrm{MD}^{\mathrm{a}}$
}

\section{ABSTRACT}

Objective: To evaluate whether the outcomes of minimally invasive aortic valve surgery were similar in younger versus older patient groups, as well as whether concomitant minimally invasive aortic valve replacement (AVR) surgeries added significant risks in these populations.

Methods: We performed a single-institution retrospective analysis of 1018 patients undergoing isolated AVR and 378 patients undergoing concomitant AVR procedures over a 6-year period. All surgeries were via a right minithoracotomy approach, and patients who underwent reoperation were excluded.

Results: Mortality was $1.3 \%$ in the isolated AVR group and 3.2\% in the concomitant AVR group. The incidence of permanent stroke was low in both the isolated and concomitant AVR groups $(0.8 \%$ and $1.1 \%$, respectively). In both groups, femoral cannulation was associated with equally low stroke rates $(0.8 \%$ and $0.6 \%$, respectively). When analyzing operative outcomes by age, mortality was similar for the isolated AVR group (age $<80$ vs $\geq 80$ years, $0.9 \%$ vs $2.2 \%$; $P=.07$ ) and the concomitant AVR group ( $<80$ vs $\geq 80$ years, $3.2 \%$ vs $3.2 \%$; $P=.99)$, whereas transfusion requirements, intensive care unit and hospital lengths of stay, and atrial fibrillation rates were greater in the older subsets of both AVR groups.

Conclusions: Minimally invasive right thoracotomy AVR surgery was associated with low stroke and mortality rates in all age groups within 30 days of surgery. Similarly, minithoracotomy concomitant AVR surgery demonstrated excellent results and is deemed feasible in patients with multiple pathologies. ( $\mathrm{J}$ Thorac Cardiovasc Surg 2018;155:926-36)

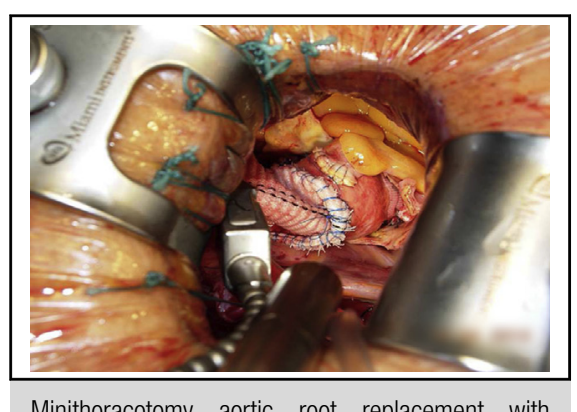

Minithoracotomy aortic root replacement with re-implantation of the coronaries.

\section{Central Message}

Minithoracotomy isolated and concomitant aortic valve surgeries are safe and expand the benefits of minimally invasive procedures.

\section{Perspective}

Minimally invasive minithoracotomy aortic valve surgery is feasible and safe in all age groups, with exceptional outcomes. Expansion of the procedure to include concomitant pathologies further demonstrates its applicability in older age groups with excellent results.

See Editorial Commentaries pages 937 and 938.
Minimally invasive aortic valve surgery has progressed through an evolution of various incisions and approaches. The concept was first introduced in 1996 by Cosgrove and Sabik. ${ }^{1}$ The authors described a right parasternal incision, which later proved to cause significant chest wall instability and has since been abandoned. Despite a plethora of data demonstrating the benefits and outstanding outcomes of

From the ${ }^{\mathrm{a} D i v i s i o n}$ of Cardiac Surgery, Mount Sinai Heart Institute, Miami Beach, Fla; 'bepartment of Cardiac Surgery, Baylor St. Luke's Medical Center; ${ }^{\mathrm{c}}$ Department of Cardiovascular Surgery, Texas Heart Institute; and ${ }^{\mathrm{d}}$ Surgical Research Core, Michael E. DeBakey Department of Surgery, Baylor College of Medicine, Houston, Tex.

Received for publication Feb 3, 2016; revisions received Aug 14, 2017; accepted for publication Sept 9, 2017; available ahead of print Oct 20, 2017.

Address for reprints: Joseph Lamelas, MD, One Baylor Plaza, MS: BCM 390, Houston, TX 77063 (E-mail: jlamelasmd@aol.com).

0022-5223/\$36.00

Copyright (c) 2017 by The American Association for Thoracic Surgery

https://doi.org/10.1016/j.jtcvs.2017.09.044 minimally invasive aortic valve surgery, most aortic valve replacement (AVR) surgeries continue to be performed via a median sternotomy. The most commonly performed minimally invasive approach is the upper hemisternotomy approach, with either a $\mathrm{T}$ or $\mathrm{L}$ transection of the sternum at the level of the third or fourth intercostal space. A lower hemisternotomy and a manubrial approach have been described as well. Alternatively, access can be achieved through a right anterior minithoracotomy, with the thoracic cavity entered via the second or third intercostal space. This

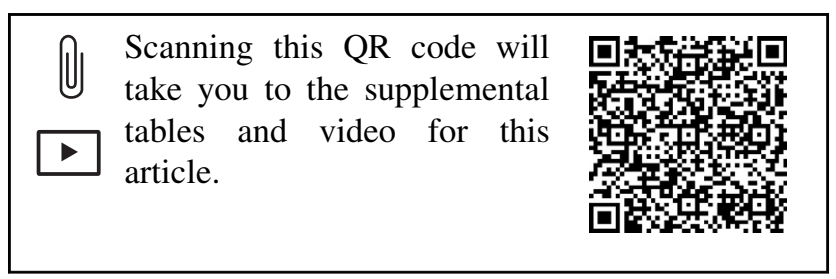



Abbreviations and Acronyms
AVR = aortic valve replacement
$\mathrm{CT}=$ computed tomography
ICU = intensive care unit
IVC = inferior vena cava
NYHA $=$ New York Heart Association
PVD = peripheral vascular disease
$\mathrm{RCP}=$ retrograde cerebral perfusion
SAVR = surgical aortic valve replacement
STS = Society of Thoracic Surgeons
SVC = superior vena cava
TAVR $=$ transcatheter aortic valve replacement

approach has not been widely adopted, however, because of its perceived technical difficulty and the variable anatomic orientation of the aorta.

The majority of minimally invasive procedures involving the ascending aorta have been limited to an upper hemisternotomy. Few reports have addressed the use of a right minithoracotomy approach for replacement of the aortic root, ascending aorta, and/or hemiarch. ${ }^{2}$ Furthermore, concomitant aortic and $\mathrm{mitral}^{3}$; concomitant aortic, mitral, and tricuspid; and concomitant aortic and coronary revascularization procedures ${ }^{4}$ performed through a minithoracotomy have been reported only sporadically. Minimally invasive valve surgery has documented benefits compared with standard median sternotomy, including reductions in surgical trauma, blood loss, transfusion requirements, reoperations for bleeding, and composite complications. In addition, most studies have demonstrated shorter ventilation times, shorter intensive care unit (ICU) and hospital lengths of stay, lower costs, less use of rehabilitative resources, and more rapid return to normal function.

In the present study, we analyzed the safety and outcomes of almost 1400 consecutive isolated and concomitant minithoracotomy aortic valve surgeries to evaluate whether concomitant procedures added additional complexities to this type of repair. Given the perception of a greater risk of surgery in patients age $\geq 80$ years and pervasive view that transcatheter valve implants should be the predominant therapy in this group, a secondary objective was to assess whether the outcomes of minimally invasive valve surgery through a right thoracotomy were similar for younger and older populations.

\section{METHODS}

On approval and a waiver of consent from our Institutional Review Board, we retrospectively reviewed a computerized database of 3081 minimally invasive right minithoracotomy heart surgeries performed at Mount Sinai Heart Institute between January 2009 and July 2015. Of these, 1018 involved a minimally invasive aortic valve surgery (isolated AVR group), and 378 involved minimally invasive AVR plus a concomitant procedure (concomitant AVR group) (Table 1). The isolated AVR group included 14 root-enlarging procedures, 38 ascending aortoplasties, and 18 septal myectomies. The concomitant procedures are listed in Table 2. All procedures requiring circulatory arrest were performed with retrograde cerebral perfusion (RCP), a method consistent with all cases performed via a median sternotomy. Selective antegrade cerebral perfusion could not be performed owing to the inability to obtain full access to the great vessels.

Patients undergoing reoperative right minithoracotomy aortic valve surgery were not included in this study. Other patients excluded from both groups included those with a porcelain aorta, as detected by cardiac catheterization; those with severe vascular disease at the time of surgery that prohibited cannulation; and those who required extensive coronary revascularization, reoperative ascending aortic surgery, complete arch reconstruction, or a valve-sparing procedure. These cases require greater exposure of the operative field.

Patients whose surgery began as a minimally invasive procedure but was subsequently converted to a median sternotomy were included in the minimally invasive group to conform to the "intention-to-treat" principle.

Data on demographics, medical history, and operative results were collected for all patients in the isolated AVR and concomitant AVR groups. Society of Thoracic Surgeons (STS) operative risk scores were not available for the majority of patients in the concomitant AVR group. The primary endpoints for analysis were death within 30 days of surgery and permanent stroke. The definitions and variables selected were based on the original STS database definitions (version 2.61). ${ }^{6}$ The 30 -day death variable includes deaths occurring after any transfer to an acute care facility.

The surgical results in the subgroups based on age $(<80$ years and $\geq 80$ years) were analyzed, taking into account that many transcatheter valve studies have demonstrated improved or equivalent outcomes in younger patients compared with surgical valve replacement in patients age $>80$ years.

\section{Preoperative Planning and Surgical Techniques}

Our minimally invasive operative technique has been described previously. ${ }^{7}$ A femoral platform with direct cutdown on the femoral vessels is the preferred method. The Seldinger technique is used for arterial and venous cannulation. Transesophageal echocardiography is used to facilitate placement of the venous cannula in the superior vena cava (SVC). Routine preoperative computed tomography (CT) angiography to screen for peripheral vascular disease (PVD) and/or aortic pathology is not performed. If significant PVD is evident during femoral cannulation, axillary artery or direct central aortic cannulation is performed.

Routine CT scans to assess the location of the ascending aorta are not performed. In our opinion, if the aortic valve is left of the midline, this does not contraindicate a minithoracotomy approach. This is in contrast to the opinion of others, who routinely use the findings of CT scans to determine exclusion parameters. ${ }^{5}$

For the aortic valve procedure, a 5- to 6-cm transverse incision is made over the right second intercostal space. After the mammary artery and vein are ligated, the inferior cartilage is transected adjacent to the sternum. Concomitant AVR and right coronary bypass surgeries are performed via this approach. Exposure of the distal right coronary artery is obtained with epicardial stay sutures, with the toe of the anastomosis performed first.

A soft tissue retractor and rib spreader are inserted. Following opening of the pericardium and placement of pericardial stay sutures, a ventricular vent is placed into the right superior pulmonary vein. The aorta is cross-clamped directly through the incision. Cardioplegia is delivered directly into the root or into each coronary ostia in the presence of aortic insufficiency. We have completely abandoned the use of retrograde cardioplegia delivery. A modified Del Nido cardioplegia solution (4 parts blood and 1 part cardioplegia) provides for at least 90 minutes of safe myocardial protection.

An aortotomy is performed $2 \mathrm{~cm}$ from the cross-clamp, and the valve is resected. Three commissural stay sutures improve visualization. 
TABLE 1. Preoperative characteristics of 1396 patients who underwent minimally invasive aortic valve replacement

\begin{tabular}{|c|c|c|c|c|}
\hline Characteristic & Isolated AVR $(\mathbf{n}=1018)$ & Concomitant AVR $(n=378)$ & Total $(n=1396)$ & $P$ value \\
\hline \multicolumn{5}{|l|}{ Age, y } \\
\hline Mean \pm SD & $72.5 \pm 11.8$ & $71.0 \pm 12.2$ & $72.1 \pm 11.9$ & .045 \\
\hline Range & $22-94$ & $26-97$ & $22-97$ & \\
\hline Age $\geq 80 \mathrm{y}, \mathrm{n}$ & $313(30.7)$ & $95(25.1)$ & $408(29.2)$ & .04 \\
\hline Male sex, n (\%) & $608(59.7)$ & $188(49.7)$ & $796(57.0)$ & .0008 \\
\hline Diabetes mellitus, n (\%) & $298(29.3)$ & $104(27.5)$ & $402(28.8)$ & .52 \\
\hline \multicolumn{5}{|l|}{ Ejection fraction, $\mathrm{mL}$} \\
\hline No. of patients & 1005 & 374 & 1379 & \\
\hline Mean $\pm \mathrm{SD}$ & $57.8 \pm 10.2$ & $55.9 \pm 11.8$ & $57.3 \pm 10.7$ & .003 \\
\hline Range & $15-78$ & $15-70$ & $15-78$ & \\
\hline Renal insufficiency, $\mathrm{n}(\%)^{*}$ & $80(7.9)$ & $35(9.3)$ & $115(8.2)$ & .40 \\
\hline Dialysis, $\mathrm{n} / \mathrm{N}(\%)$ & $14 / 1015(1.4)$ & $13 / 377(3.4)$ & 27/1392 (1.9) & .013 \\
\hline Hypertension, n (\%) & $884(86.8)$ & $331 / 376(88.0)$ & $1215 / 1394(87.2)$ & .55 \\
\hline Chronic lung disease, n (\%) & $173(17.0)$ & $59(15.6)$ & $232(16.6)$ & .54 \\
\hline \multicolumn{5}{|l|}{ Heart failure, $\mathrm{n} / \mathrm{N}(\%)$} \\
\hline Previous & $246 / 1005(24.5)$ & $123 / 372(33.1)$ & $369 / 1377(26.8)$ & .001 \\
\hline Within $2 \mathrm{wk}$ & $124 / 981(12.6)$ & $63 / 356(17.7)$ & $187 / 1337(14.0)$ & .018 \\
\hline \multicolumn{5}{|l|}{ NYHA class, n (\%) } \\
\hline $\mathrm{I} / \mathrm{II}$ & $133(13.1)$ & $67(17.7)$ & $200(14.3)$ & .027 \\
\hline III/IV & $124(12.2)$ & $63(16.7)$ & $187(13.4)$ & .029 \\
\hline Peripheral vascular disease, $\mathrm{n}(\%)$ & $113(11.1)$ & $43(11.4)$ & $156(11.2)$ & .88 \\
\hline Previous CVA, n/N (\%) & $59 / 1018(5.8)$ & $22 / 378(5.8)$ & $81 / 1396(5.8)$ & .80 \\
\hline Coronary artery disease, $\mathrm{n} / \mathrm{N}(\%)$ & $246 / 1018(24.2)$ & $100 / 378(26.5)$ & $346 / 1396(24.8)$ & .82 \\
\hline Previous MI, n/N (\%) & $131 / 1018(12.9)$ & $57 / 378(15.1)$ & $188 / 1396(13.5)$ & - \\
\hline Previous PCI, n/N (\%) & $177 / 1018(17.4)$ & $65 / 378(17.2)$ & $242 / 1396(17.3)$ & - \\
\hline Family history, n/N (\%) & $58 / 951(6.1)$ & $17 / 352(4.8)$ & $75 / 1303(5.8)$ & .38 \\
\hline \multicolumn{5}{|l|}{ Aortic valve } \\
\hline Stenosis, $\mathrm{n} / \mathrm{N}(\%)$ & 923/1004 (91.9) & $282 / 360(78.3)$ & $1205 / 1364(88.3)$ & $<.0001$ \\
\hline Insufficiency, n/N (\%) & $840 / 956(87.9)$ & $335 / 369(90.8)$ & $1175 / 1325(88.7)$ & .13 \\
\hline Endocarditis, n (\%) & $17(1.7)$ & $20(5.3)$ & $37(2.7)$ & .0002 \\
\hline \multicolumn{5}{|l|}{ Creatinine level, mg/dL } \\
\hline Median (IQR) & $0.9(0.8-1.2)$ & $0.9(0.8-1.2)$ & $0.9(0.8-1.2)$ & .75 \\
\hline Range & $0.1-9.2$ & $0.1-9.5$ & $0.1-9.5$ & \\
\hline \multicolumn{5}{|l|}{ STS score } \\
\hline No. of patients & 910 & 20 & 930 & \\
\hline Mean $\pm \mathrm{SD}$ & $2.3 \pm 1.8$ & $3.1 \pm 2.0$ & $2.3 \pm 1.8$ & .058 \\
\hline Range & $0.4-14.3$ & $0.9-8.5$ & $0.4-14.3$ & \\
\hline
\end{tabular}

$A V R$, Aortic valve replacement; $S D$, standard deviation; $N Y H A$, New York Heart Association; $C V A$, cerebrovascular accident; $M I$, myocardial infarction; $P C I$, percutaneous coronary intervention; IQR, interquartile range; STS, Society of Thoracic Surgeons. *Renal insufficiency defined as creatinine $>1.5 \mathrm{mg} / \mathrm{dL}$.

A specially designed aortic wall retractor (Aortic Cuff, Miami Instruments, Miami, Fla) provides additional exposure of the annulus. Valve replacement techniques proceed in a conventional fashion with the aid of longshafted instruments and a knot setter. A ventricular pacing wire is placed on the inferior wall of the right ventricle before unclamping. Air removal is performed by venting the aortic root and left ventricle under guidance by transesophageal echocardiography.

After weaning from cardiopulmonary bypass and protamine administration, the femoral venous and arterial cannulas are removed. One Blake chest tube is placed over the pulmonary artery into the pericardial space, and another is placed in the right pleural space. The chest tubes, pacing wire, and pain pump catheters (On-Q; Halyard, Irvine, Calif) are tunneled through the chest tube incision. The dislocated rib is reattached to the sternum, and a figure- 8 suture is placed around the ribs to provide chest wall stabilization.

Aortic root replacement with coronary reimplantation is performed through the second intercostal space, similar to the approach for isolated AVR surgery. The operation is performed much like isolated AVR surgery. The aorta is transected close to the sinotubular junction, the aortic valve is resected, and coronary buttons are established. Stay sutures placed at the 
TABLE 2. Concomitant procedures performed in 378 patients who underwent minimally invasive aortic valve replacement and repair*

\begin{tabular}{lr}
\hline \multicolumn{1}{c}{ Procedure } & No. \\
\hline Aortic valve replacement & \\
+ AA & 58 \\
Circulatory arrest & 1 \\
$\quad$ No circulatory arrest & 215 \\
+ MVR & \\
+ AA and MVR & 5 \\
Circulatory arrest & 8 \\
No circulatory arrest & 23 \\
+ CABG & 7 \\
+ CABG and MVR & 1 \\
+ TVR & 7 \\
+ TVR and MVR & 28 \\
+ Maze procedure & \\
Aortic valve repair & \\
+ AA & 3 \\
Circulatory arrest & 9 \\
No circulatory arrest & \\
+ MVR and TVR & 2 \\
+ AV repair & 2 \\
Aortic root, reimplantation of coronaries & \\
Circulatory arrest & 9 \\
No circulatory arrest & 9 \\
\hline
\end{tabular}

$A A$, Ascending aorta (replacement); $M V R$, mitral valve repair/replacement (includes all); $C A B G$, coronary artery bypass graft; $T V R$, tricuspid valve repair/replacement (includes all); $A V$, aortic valve. ${ }^{*}$ The table does not include 6 isolated AA replacements and $3 \mathrm{AA}$ and MVRs that were performed during the study period because they were not concomitant with an aortic valve replacement or repair.

level of the commissures facilitate exposure. The inflow suture line is buttressed over a felt strip, necessitating the use of a knot-tying tool owing to the depth of the field. The left main followed by the right coronary are anastomosed to the root with long-shafted instruments.

For the concomitant AVR and supracoronary ascending aortic replacements, either a second or third interspace AVR approach or a more lateral fourth or fifth interspace mitral valve approach incision is used. In the latter approach, the patient's arm is positioned over the head. The choice between these approaches is arbitrary; both are feasible, although the hemiarch anastomosis is further away with a fourth or fifth interspace incision, despite improved visualization of the entire aorta. In all patients requiring replacement of the hemiarch, RCP is used with a separate $24 \mathrm{Fr}$ venous cannula tunneled from the chest tube incision into the SVC. The SVC is snared during RCP. All patients are cooled to $20^{\circ} \mathrm{C}$, and a meticulous 2-layer distal anastomosis is performed. Additional pericardial stay sutures facilitate exposure of the hemiarch. The graft is clamped, the patient is rewarmed, and AVR proceeds in the usual fashion. The graft is expanded with blood and clamped distally while the heart is filled. The most posterior aspect where both grafts meet is the point of resection of the distal graft. A beveled transection is preferred. Cases with more extensive involvement of the arch were excluded from this study.

All double (aortic + mitral) $($ Video 1$)$ and triple $($ aortic + mitral + tricuspid) valve surgeries are performed through a lateral fourth or fifth interspace approach with the arm elevated. The incision is located lateral to the anterior axillary line and superior to the middle of the entire sternum. Pericardial stay sutures are placed at the level of the inferior vena cava (IVC), pulmonary veins, and SVC. Additional stay sutures are placed on the pericardium lateral to the distal aorta to provide further retraction toward the operative field. The aorta is directly clamped through the incision. After cardioplegia is delivered, a $\mathrm{U}$-shaped incision is made in

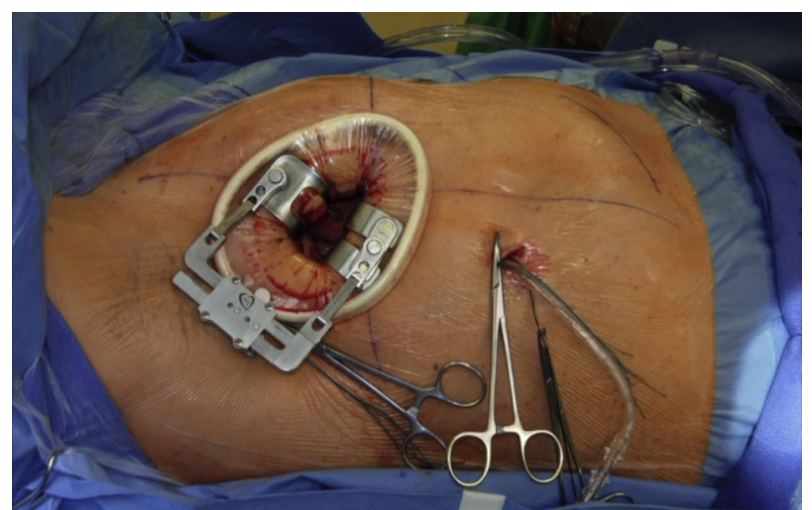

VIDEO 1. Minimally invasive right thoracotomy aortic valve replacement and complex mitral valve repair with chordae. Video available at: http:// www.jtcvsonline.org/article/S0022-5223(17)31961-X/fulltext.

the aorta. The most inferior aspect of the incision is positioned deep in the noncoronary sinus, to allow for improved visibility of the aortic annulus. The left atrium is opened, and a sump suction is placed in the left pulmonary veins. After resection and debridement of the aortic annulus, the mitral valve is addressed. An atrial lift retractor is used to improve visibility of the mitral valve. Conventional techniques are performed with long-shafted instruments to address the mitral valve. Essentially, any complex mitral repair can be performed with this exposure. Patients with mitral annular calcification were not excluded from this study. Once the repair is completed, a sump suction is placed in the left atrium, and the atriotomy is partially closed.

For tricuspid valve surgery, the SVC and IVC are encircled with vessel loops. Both the SVC and IVC are snared, the femoral venous cannula is withdrawn into the IVC, and the right atrium is opened. A second sump suction, tunneled through the chest tube incision, is then placed directly into the SVC through the atriotomy once the SVC snare is temporarily released. The tricuspid surgery proceeds in the usual fashion with the aid of the atrial lift retractor. The atriotomy is closed in a 2-layer fashion. A stay suture is placed on the superior aspect of the aorta, and commissural sutures provide further retraction and exposure of the aortic annulus. The aortic valve is then implanted. The noncoronary sutures are tied first, because these are typically the most difficult to access. The aortotomy is closed in a 2-layer fashion. A ventricular pacing wire and aortic root vent are placed. Once removal of air is complete, 2 drainage tubes are positioned, and a figure- 8 suture is used to approximate the ribs.

\section{Statistical Analysis}

Continuous variables with a normal distribution were analyzed using the Student $t$ test. The Mann-Whitney $U$ test was used for nonparametric variables. All dichotomous variables were compared using the $\chi^{2}$ test. A $P$ value $<.05$ was considered to indicate statistical significance. Statistical analyses were performed using SAS version 9.4 (SAS Institute, Cary, NC).

\section{Propensity Score Matching}

Given the low number of postoperative complications, we used propensity score matching to better assess risk between groups of patients. We defined 2 treatment groups - isolated AVR and concomitant AVR - and 2 age subgroups-age $<80$ years and age $\geq 80$ years-within each of the AVR groups. We estimated the propensity score using a multivariate logistic regression model and treated missing values as separate categories. The following preoperative covariates (presented in Table 1) were used to generate propensity scores: sex, diabetes, prior heart failure, prior heart failure within 2 weeks of repair, left ventricular ejection fraction, renal dialysis, renal insufficiency, serum creatinine level, hypertension, coronary artery disease, family history of coronary artery disease, chronic lung 
disease, peripheral vascular disease, aortic valve stenosis, aortic valve insufficiency, infectious endocarditis, New York Heart Association (NYHA) class III/IV, and age (not in the model for age groups). The STS risk score and previous cerebrovascular accident variables were not included with the other preoperative variables when building the propensity score groups, because a substantial number of values were missing from the concomitant AVR group. One-to-one nearest-neighbor matching without replacement was performed with a caliper width equal to 0.01 standard deviation. The balance of preoperative covariates was examined using standardized differences. Propensity score matching was carried out using Stata version 14 (StataCorp, College Station, Tex). Rates of 30-day mortality and postoperative stroke were compared between treatment groups using McNemar's test after propensity score matching.

\section{RESULTS}

\section{Patient Characteristics}

Table 1 presents demographic data and medical history details for the entire study population, as well as for the isolated AVR and concomitant AVR groups. The mean $\pm \mathrm{SD}$ age was slightly higher in the isolated AVR group than in the concomitant AVR group: $72.5 \pm 11.8$ versus $71.0 \pm 12.2(P=.045)$. The mean ejection fraction and the range were similar in the isolated and concomitant groups (mean, $57.8 \pm 10.2 \%$ vs $55.9 \pm 11.8 \%$; range, $15 \%-78 \%$ vs $15 \%-70 \%)$. The isolated AVR group included a significantly higher percentage of males and patients with aortic stenosis, but a lower percentage of patients receiving dialysis or with endocarditis. The concomitant AVR group had more patients with a previous history of heart failure $(33.1 \%$ vs $24.5 \% ; P=.001)$, as well as more patients with NYHA class III/IV $(16.7 \%$ vs $12.2 \% ; P=.029)$.

\section{Operative Outcomes}

Mortality was lower in the isolated AVR group, as compared to the concomitant AVR group (1.3\% vs 3.2\%; $P=.018$ ) (Table 3). In contrast, the incidence of permanent stroke was similar in both groups $(0.8 \%$ and $1.1 \%$, respectively; $P=.62$ ). The incidence of permanent stroke did not differ, even during the subgroup analysis of patients undergoing femoral cannulation (isolated AVR: $0.8 \%$; concomitant AVR: $0.6 \% ; P=.71$ ). The rate of reoperation for bleeding rate, transfusion requirements, duration of ventilation, ICU and hospital lengths of stay, conversion rates, perfusion times, and cross-clamp times were all significantly lower in the isolated AVR group. Postoperative atrial fibrillation and pacemaker implantation rates were similar in the 2 groups. There were 8 conversions to median sternotomy, including 2 in the isolated AVR group and 6 in the concomitant AVR group (which resulted in 1 death in the concomitant AVR group).

\section{Isolated AVR Surgery Stratified by Advanced Age ( $\geq 80$ Years)}

Among the patients who underwent isolated AVR surgery, 705 were age $<80$ years and 313 were age $\geq 80$ years. The 30 -day mortality rate was twice as high in the older group, with a difference approaching statistical significance $(0.9 \%$ and $2.2 \%$, respectively; $P=.07)$ (Table 4). The older age group had statistically significantly higher percentages of patients in NYHA class III/IV (16.9\% vs $10.1 \% ; P=.002)$, patients with heart failure within 2 weeks $(17.8 \%$ vs $10.4 \% ; P=.001)$, and patients with previous heart failure $(32.5 \%$ vs $20.9 \% ; P<.0001)$ (Table E1). The rate of permanent stroke was similar in both age groups $(0.6 \%$ for $<80$ years and $1.3 \%$ for $\geq 80$ years; $P=.24$ ), even when considering those who underwent femoral cannulation $(0.6 \%$ and $1.1 \%$, respectively; $P=.45)$. Femoral cannulation was performed in $>88 \%$ of patients undergoing isolated AVR. Transfusion requirements, ventilation duration, atrial fibrillation, ICU and hospital lengths of stay, and STS scores were significantly greater in the older group. The number of units of packed red blood cells transfused differed between the groups, with $52.9 \%$ of the younger group versus $24.0 \%$ of the older group not receiving any transfusions. Surprisingly, the cross-clamp times and perfusion times were longer in the younger group. The rates of reoperation for bleeding and conversion were similar in the 2 age groups (Table 4).

\section{Concomitant AVR Surgery Stratified by Advanced Age ( $\geq 80$ Years)}

The patients who underwent concomitant AVR surgery included 283 age $<80$ years and 95 age $\geq 80$ years. The 30-day mortality rate was $3.2 \%$ in both age groups (Table 5). The $<80$ age group contained more males $(54.4 \%$ vs $35.8 \% ; P=.002)$ and more patients with a history of endocarditis $(6.7 \%$ vs $1.1 \% ; P=.033)$ (Table E2). Although one-third of all patients had a previous history of heart failure, the percentages of those who underwent surgery in NYHA class I/II and class III/IV were similar $(17.7 \%$ and $16.7 \%$, respectively). The permanent stroke rate was slightly higher in the older age group $(2.1 \%$ vs $0.7 \% ; P=.25)$. In patients who underwent femoral cannulation, the permanent stroke rate was significantly lower in the $<80$-year-old group compared with the $\geq 80$-year-old group $(0.0 \%$ vs $2.5 \% ; P=.01)$. The stroke rate was not higher in patients requiring circulatory arrest and RCP. One patient age $\geq 80$ years who underwent circulatory arrest had postoperative bleeding requiring a conversion and then suffered a stroke. There was 1 death in the concomitant AVR group, in a patient age $\geq 80$ who had circulatory arrest. Transfusion requirements, atrial fibrillation, and ICU and hospital lengths of stay were significantly greater in the older group. More patients in the younger group did not receive transfusions $(40.3 \%$ vs $12.6 \%)$. Surprisingly, the cross-clamp and perfusion times were also longer in the younger group. The reoperation rate, ventilation time, 
TABLE 3. Operative results for 1396 patients who underwent minimally invasive aortic valve replacements

\begin{tabular}{|c|c|c|c|c|}
\hline Outcome & Isolated AVR $(n=1018)$ & Concomitant AVR $(n=378)$ & Total $(n=1396)$ & $P$ value \\
\hline 30-d mortality, n (\%) & $13(1.3)$ & $12(3.2)$ & $25(1.8)$ & .018 \\
\hline Reoperation for bleeding, $\mathrm{n}(\%)$ & $8(0.8)$ & $8(2.1)$ & $16(1.1)$ & .038 \\
\hline $\begin{array}{l}\text { Total RBC units transfused, } \mathrm{n}(\%) \\
0 \\
1-2 \\
3+\end{array}$ & $\begin{array}{l}448(44.0) \\
352(34.6) \\
218(21.4)\end{array}$ & $\begin{array}{l}126(33.3) \\
131(34.7) \\
121(32.0)\end{array}$ & $\begin{array}{l}574(41.1) \\
483(34.6) \\
339(24.3)\end{array}$ & $<.0001$ \\
\hline $\begin{array}{l}\text { Ventilation time, } \mathrm{h} \\
\text { Median (IQR) } \\
\text { Range }\end{array}$ & $\begin{array}{c}8.7(4.7-16.9) \\
1.2-1590.5\end{array}$ & $\begin{array}{c}12.5(5.5-20.8) \\
1.0-2936.8\end{array}$ & $\begin{array}{c}9.4(4.9-18.2) \\
1.0-2936.8\end{array}$ & $<.0001$ \\
\hline Postoperative atrial fibrillation, n (\%) & $231(22.7)$ & $79(20.9)$ & $310(22.2)$ & .47 \\
\hline Postoperative pacemaker, n (\%) & $32(3.1)$ & $14(3.7)$ & $46(3.3)$ & .60 \\
\hline $\begin{array}{l}\text { Permanent stroke, } \mathrm{n}(\%) \\
\text { Femoral cannulation only, n/N (\%) }\end{array}$ & $\begin{array}{c}8(0.8) \\
7 / 900(0.8)\end{array}$ & $\begin{array}{c}4(1.1) \\
2 / 347(0.6)\end{array}$ & $\begin{array}{c}12(0.9) \\
9 / 1247(0.7)\end{array}$ & $\begin{array}{l}.62 \\
.71\end{array}$ \\
\hline $\begin{array}{l}\text { ICU LOS, h } \\
\text { Median (IQR) } \\
\text { Range }\end{array}$ & $\begin{array}{c}38.9(24.6-64.0) \\
12.4-1753.1\end{array}$ & $\begin{array}{l}45.4(24.6-88.4) \\
9.0-1778.4\end{array}$ & $\begin{array}{c}41.8(24.6-69.3) \\
9.0-1778.4\end{array}$ & .0009 \\
\hline $\begin{array}{l}\text { Hospital LOS, d } \\
\text { Median (IQR) } \\
\text { Range }\end{array}$ & $\begin{array}{c}6(4-8) \\
1-95\end{array}$ & $\begin{array}{c}7(5-10) \\
3-148\end{array}$ & $\begin{array}{c}6(4-8) \\
1-148\end{array}$ & $<.0001$ \\
\hline Conversions, $\mathrm{n}(\%)$ & $2(0.2)$ & $6(1.6)$ & $8(0.6)$ & .002 \\
\hline $\begin{array}{l}\text { Perfusion time, min } \\
\text { No. of patients } \\
\text { Median (IQR) } \\
\text { Range }\end{array}$ & $\begin{array}{c}1017 \\
101(88-119) \\
54-403\end{array}$ & $\begin{array}{c}377 \\
148(124-182) \\
10-358\end{array}$ & $\begin{array}{c}1394 \\
110(92-138) \\
10-403\end{array}$ & $<.0001$ \\
\hline $\begin{array}{l}\text { Cross-clamp time, min } \\
\text { No. of patients } \\
\text { Median (IQR) } \\
\text { Range }\end{array}$ & $\begin{array}{c}1015 \\
76(65-90) \\
41-356\end{array}$ & $\begin{array}{c}377 \\
117(93-142) \\
27-258\end{array}$ & $\begin{array}{c}1392 \\
83(68-106) \\
27-356\end{array}$ & $<.0001$ \\
\hline
\end{tabular}

$A V R$, Aortic valve replacement; $R B C$, red blood cell; $I Q R$, interquartile range; $I C U$, intensive care unit; $L O S$, length of stay.

number of conversions, and rate of pacemaker implantation were similar in the 2 age groups.

\section{Propensity Score Matching}

Using the foregoing protocol, we were unable to successfully match patients by octogenarian status (age $<80$ years vs age $\geq 80$ years) given the relatively small number of octogenarians in the concomitant AVR group. However, we were able to match 296 patients from the concomitant AVR group with 296 patients who underwent an isolated AVR procedure. Distributions of preoperative covariates were balanced in the matched datasets (Table 6). Absolute standardized differences $<0.1$ showed negligible differences between the treatment groups. In the matched dataset, 30-day mortality rate and neurologic postoperative outcome were not significantly different between the treatment groups. The 30-day mortality rates were $2.0 \%$ for the isolated AVR group and $3.7 \%$ for the concomitant AVR group $(P=.0625)$, and the permanent stroke rates were $3.0 \%$ and $3.1 \%$, respectively $(P=1.0)$.

\section{DISCUSSION}

This single-center, single-surgeon series of almost 1400 minimally invasive isolated and concomitant AVR operations demonstrates the safety of the procedure performed via a right minithoracotomy approach. We also chose to compare the outcomes of patients older and younger than 80 years in both cohorts since many of the transcatheter studies focus on the results in this older population. Our overall 30-day mortality rate in the isolated right thoracotomy AVR group was $1.3 \%$, and the subgroup analysis of death by octogenarian status was almost double that in patients age $<80$ years $(2.2 \%$ vs $0.9 \%)$, although the difference was not statistically significant. The overall permanent stroke rate was $0.8 \%$, and the rate was not higher in those undergoing femoral cannulation. This finding is similar to the $1.1 \%$ rate reported in our previous study of minimally invasive valve surgery. ${ }^{8}$ In a study population of 67,292 patients from the STS database from 2002 to 2006 , the unadjusted mortality rate was $3.2 \%$, and the stroke rate was $1.5 \%{ }^{6}$ Thourani and colleagues ${ }^{9}$ analyzed the real-world data of 78,151 patients (PROM groups) 
TABLE 4. Operative results for 1018 patients who underwent isolated minimally invasive aortic valve replacement, stratified by advanced age

\begin{tabular}{|c|c|c|c|c|}
\hline Outcome & Age $<80$ y $(n=705)$ & Age $\geq 80$ y $(n=313)$ & Total $(\mathbf{n}=1018)$ & $P$ value \\
\hline 30-d mortality, n (\%) & $6(0.9)$ & $7(2.2)$ & $13(1.3)$ & .07 \\
\hline Reoperation for bleeding, $\mathrm{n}(\%)$ & $4(0.6)$ & $4(1.3)$ & $8(0.8)$ & .24 \\
\hline $\begin{array}{l}\text { Total RBC units transfused, } \mathrm{n}(\%) \\
\quad 0 \\
1-2 \\
3+\end{array}$ & $\begin{array}{l}373(52.9) \\
220(31.2) \\
112(15.9)\end{array}$ & $\begin{array}{l}75(24.0) \\
132(42.2) \\
106(33.9)\end{array}$ & $\begin{array}{l}448(44.0) \\
352(34.6) \\
218(21.4)\end{array}$ & $<.0001$ \\
\hline $\begin{array}{l}\text { Ventilation time, } \mathrm{h} \\
\text { Median (IQR) } \\
\text { Range }\end{array}$ & $\begin{array}{c}8.0(4.6-16.3) \\
1.2-1048.9\end{array}$ & $\begin{array}{c}10.7(5.3-19.0) \\
2.1-1590.5\end{array}$ & $\begin{array}{c}8.7(4.7-16.9) \\
1.2-1590.5\end{array}$ & .002 \\
\hline Postoperative atrial fibrillation, n (\%) & $141(20.0)$ & $90(28.8)$ & $231(22.7)$ & .002 \\
\hline Postoperative pacemaker, $\mathrm{n}(\%)$ & $18(2.6)$ & $14(4.5)$ & $32(3.1)$ & .11 \\
\hline $\begin{array}{l}\text { Permanent stroke, } \mathrm{n}(\%) \\
\text { Femoral cannulation only, n/N (\%) }\end{array}$ & $\begin{array}{c}4(0.6) \\
4 / 631(0.6)\end{array}$ & $\begin{array}{c}4(1.3) \\
3 / 269(1.1)\end{array}$ & $\begin{array}{c}8(0.8) \\
7 / 900(0.8)\end{array}$ & $\begin{array}{l}.24 \\
.45\end{array}$ \\
\hline $\begin{array}{l}\text { ICU LOS, h } \\
\text { Median (IQR) } \\
\text { Range }\end{array}$ & $\begin{array}{c}33.3(24.3-50.6) \\
12.4-1097.8\end{array}$ & $\begin{array}{c}46.1(26.3-90.5) \\
13.5-1753.1\end{array}$ & $\begin{array}{c}38.9(24.6-64) \\
12.4-1753.1\end{array}$ & $<.0001$ \\
\hline $\begin{array}{l}\text { Hospital LOS, d } \\
\text { Median (IQR) } \\
\text { Range }\end{array}$ & $\begin{array}{c}5(4-7) \\
1-67\end{array}$ & $\begin{array}{c}7(5-9) \\
4-95\end{array}$ & $\begin{array}{c}6(4-8) \\
1-95\end{array}$ & $<.0001$ \\
\hline Conversions, $\mathrm{n}(\%)$ & $2(0.3)$ & $0(0.0)$ & $2(0.2)$ & .35 \\
\hline $\begin{array}{l}\text { Perfusion time, min } \\
\text { No. of patients } \\
\text { Median (IQR) } \\
\text { Range }\end{array}$ & $\begin{array}{c}705 \\
105(91-124) \\
54-403\end{array}$ & $\begin{array}{c}312 \\
94(84-110) \\
60-188\end{array}$ & $\begin{array}{c}1017 \\
101(88-119) \\
54-403\end{array}$ & $<.0001$ \\
\hline $\begin{array}{l}\text { Cross-clamp time, min } \\
\text { No. of patients } \\
\text { Median (IQR) } \\
\text { Range }\end{array}$ & $\begin{array}{c}703 \\
80(67-95) \\
41-356\end{array}$ & $\begin{array}{c}312 \\
70(61-81.5) \\
42-149\end{array}$ & $\begin{array}{c}1015 \\
76(65-90) \\
41-356\end{array}$ & $<.0001$ \\
\hline
\end{tabular}

$R B C$, Red blood cell; $I Q R$, interquartile range; $I C U$, intensive care unit; $L O S$, length of stay.

from 2007 to 2010 ; the in-hospital mortality rate was $2.5 \%$, and the stroke rate was $1.6 \%$. Agarwal and colleagues ${ }^{10}$ reviewed the stroke rate in 47,375 patients undergoing an isolated sternotomy AVR over a 10-year period from the Nationwide Inpatient Sample database; the incidence of any neurologic event was $1.3 \%$ for patients age $<70$ years and increased to $3.2 \%$ in those age $>85$ years. All available literature reports equal or lower incidence of stroke with a minimally invasive AVR, as compared to a sternotomy. ${ }^{11-14}$

In our concomitant AVR group, the overall mortality rate was $3.2 \%$ and did not differ by subgroup analysis by age. The overall permanent stroke rate was $1.1 \%$, although it was slightly higher in those age $\geq 80$ years. Nicolini and colleagues ${ }^{15}$ performed a subgroup analysis according to age in concomitant AVR and mitral valve surgery. The analysis demonstrated a $7.1 \%$ mortality rate in those age $>70$ years and a $14.8 \%$ mortality rate in those age $>80$ years.

There is a distinct learning curve associated with minithoracotomy surgery that may limit its widespread reproducibility. Adoption also may improve with the incorporation of these techniques in training programs. We have previously described a 5-step approach to successfully building a minimally invasive program. These steps include building a dedicated team, administrative support, training in an experienced center with subsequent proctoring, marketing, and, finally, operating on well-selected patients. ${ }^{16}$

Minimally invasive AVR has repeatedly demonstrated similar, if not superior, results when compared to sternotomy-based procedures. ${ }^{5,17-19}$ Furthermore, when comparing the outcomes of minithoracotomy to those of ministernotomy, Miceli and colleagues ${ }^{20}$ demonstrated less atrial fibrillation and shorter ventilation times and ICU and hospital length of stays for the minithoracotomy patients but similar perfusion times, stroke rates, transfusions, and reexploration in both groups. Multiple studies of patients undergoing a minithoracotomy have confirmed these findings, as well as a quicker return to a normal lifestyle, fewer postoperative composite complications, and improved cosmesis among minithoracotomy 
TABLE 5. Operative results for 378 patients who underwent concomitant minimally invasive aortic valve replacements, stratified by advanced age

\begin{tabular}{|c|c|c|c|c|}
\hline Outcome & Age $<80$ y $(n=283)$ & Age $\geq 80$ y $(n=95)$ & Total $(n=378)$ & $P$ value \\
\hline 30-d mortality, n (\%) & $9(3.2)$ & $3(3.2)$ & $12(3.2)$ & .99 \\
\hline Reoperation for bleeding, $\mathrm{n}(\%)$ & $7(2.5)$ & $1(1.1)$ & $8(2.1)$ & .41 \\
\hline $\begin{array}{l}\text { Total RBC units transfused, } \mathrm{n}(\%) \\
0 \\
1-2 \\
3+\end{array}$ & $\begin{array}{l}114(40.3) \\
90(31.8) \\
79(27.9)\end{array}$ & $\begin{array}{l}12(12.6) \\
41(43.2) \\
42(44.2)\end{array}$ & $\begin{array}{l}126(33.3) \\
131(34.7) \\
121(32.0)\end{array}$ & $<.0001$ \\
\hline $\begin{array}{l}\text { Ventilation time, } \mathrm{h} \\
\text { Median (IQR) } \\
\text { Range }\end{array}$ & $\begin{array}{c}12.3(5.3-21.5) \\
1.0-2936.8\end{array}$ & $\begin{array}{c}14.0(6.7-20.3) \\
1.7-787.5\end{array}$ & $\begin{array}{c}12.5(5.5-20.8) \\
1.0-2936.8\end{array}$ & .50 \\
\hline Postoperative atrial fibrillation, $\mathrm{n}(\%)$ & $50(17.7)$ & $29(30.5)$ & 79 (20.9) & .008 \\
\hline Postoperative pacemaker, $\mathrm{n}(\%)$ & $11(3.9)$ & $3(3.2)$ & $14(3.7)$ & .74 \\
\hline $\begin{array}{l}\text { Permanent stroke, } \mathrm{n}(\%) \\
\text { Femoral cannulation only, n/N (\%) }\end{array}$ & $\begin{array}{c}2(0.7) \\
0 / 267(0.0)\end{array}$ & $\begin{array}{c}2(2.1) \\
2 / 80(2.5)\end{array}$ & $\begin{array}{c}4(1.1) \\
2 / 347(0.6)\end{array}$ & $\begin{array}{l}.25 \\
.010\end{array}$ \\
\hline $\begin{array}{l}\text { ICU LOS, h } \\
\text { Median (IQR) } \\
\text { Range }\end{array}$ & $\begin{array}{c}43.8(24.5-72.6) \\
9-1778.4\end{array}$ & $\begin{array}{c}51.1(26.2-121.2) \\
17.2-788.4\end{array}$ & $\begin{array}{l}45.4(24.6-88.4) \\
9-1778.4\end{array}$ & .029 \\
\hline $\begin{array}{l}\text { Hospital LOS, d } \\
\text { Median (IQR) } \\
\text { Range }\end{array}$ & $\begin{array}{c}7(5-10) \\
3-148\end{array}$ & $\begin{array}{c}7(6-12) \\
4-59\end{array}$ & $\begin{array}{c}7(5-10) \\
3-148\end{array}$ & .015 \\
\hline Conversions, $\mathrm{n}(\%)$ & $3(1.1)$ & $3(3.2)$ & $6(1.6)$ & .16 \\
\hline $\begin{array}{l}\text { Perfusion time, min } \\
\text { No. of patients } \\
\text { Median (IQR) } \\
\text { Range }\end{array}$ & $\begin{array}{c}282 \\
154(132-188) \\
10-313\end{array}$ & $\begin{array}{c}95 \\
130(106-156) \\
77-358\end{array}$ & $\begin{array}{c}377 \\
148(124-182) \\
10-358\end{array}$ & $<.0001$ \\
\hline $\begin{array}{l}\text { Cross-clamp time, min } \\
\text { No. of patients } \\
\text { Median (IQR) } \\
\text { Range }\end{array}$ & $\begin{array}{c}282 \\
121(101-147) \\
27-258\end{array}$ & $\begin{array}{c}95 \\
98(79-122) \\
56-238\end{array}$ & $\begin{array}{c}377 \\
117(93-142) \\
27-258\end{array}$ & $<.0001$ \\
\hline
\end{tabular}

$R B C$, Red blood cell; $I Q R$, interquartile range; $I C U$, intensive care unit; $L O S$, length of stay.

patients. ${ }^{13,20}$ This has also been evident in hybrid cases (ie, percutaneous intervention followed by valve surgery). ${ }^{19}$ High-risk groups, including obese patients, ${ }^{3}$ frail and/or elderly patients, ${ }^{21}$ and patients with pulmonary hypertension or poor left ventricular function, benefit from a reduction in the rates for mortality, stroke, reoperation for bleeding, prolonged ventilation, and renal failure. ${ }^{3,22,23}$ In addition, patients with chronic obstructive pulmonary disease benefit from earlier extubation, improved chest wall mechanics, and decreased respiratory muscle weakness. ${ }^{24}$ Avoiding any sternal invasion eliminates sternal wound infections and promotes chest wall stability. A minithoracotomy approach permits accelerated postoperative mobility, unimpeded pulmonary physiotherapy, and potentially improves respiratory mechanics. It also decreases the amount of mediastinal dissection and avoids sternal bone invasion, leading to a low incidence of postoperative bleeding requiring reexploration. Another aspect that has received little attention in the literature is the psychological benefits of avoiding a sternotomy, especially in younger patients.
Some studies have even demonstrated long-term survival benefits with minimally invasive surgery. ${ }^{1}$

In contrast, however, other studies have claimed that less invasive cardiac surgery is not beneficial, asserting that the longer duration of cardiopulmonary bypass plus the limited exposure may outweigh any potential benefits. ${ }^{25}$ Skeptics claim that technical challenges lead to conforming the patient to the operation. Nevertheless, virtually any aortic valve procedure, except a valve-sparing surgery, can be performed via a minithoracotomy by an experienced surgeon. $^{2}$ Despite this, the majority of the minimally invasive AVRs are performed via an upper hemisternotomy. This may be attributed to a more familiar operative field. We have also demonstrated the feasibility of replacing the ascending aorta and hemiarch through a minithoracotomy.

The incidence of conversions in our isolated AVR group was low $(0.2 \%)$; the conversions were attributed to uncontrollable bleeding, lack of visibility of the aortic valve, or a heavily calcified aorta that was not suspected preoperatively. There were no associated mortalities in these cases. Most studies have reported a conversion rate 
TABLE 6. Comparison of preoperative variables and primary outcomes between isolated and concomitant aortic valve replacement groups in 296 propensity-matched pairs

\begin{tabular}{|c|c|c|c|}
\hline Variables/Outcomes & Isolated AVR $(n=296)$ & Concomitant AVR $(n=296)$ & SMD \\
\hline \multicolumn{4}{|l|}{ Preoperative variables } \\
\hline Age, $y$, mean \pm SD & $70.7 \pm 13.6$ & $71.2 \pm 12.0$ & .042 \\
\hline Male sex, $\mathrm{n}(\%)$ & $144(48.6)$ & $154(52.0)$ & .068 \\
\hline Diabetes mellitus, n (\%) & $80(27.0)$ & $74(25.0)$ & .045 \\
\hline Ejection fraction, $\mathrm{mL}$, mean $\pm \mathrm{SD}$ & $56.67 \pm 11.07$ & $56.26 \pm 11.69$ & .037 \\
\hline Renal insufficiency, n (\%) & $23(7.8)$ & $23(7.8)$ & 0 \\
\hline Dialysis, n (\%) & $6(2.0)$ & $7(2.4)$ & .021 \\
\hline Hypertension, n (\%) & $256(86.5)$ & $255(86.1)$ & .01 \\
\hline Chronic lung disease, $\mathrm{n}(\%)$ & $42(14.2)$ & $46(15.5)$ & .036 \\
\hline \multicolumn{4}{|l|}{ Heart failure, $\mathrm{n}(\%)$} \\
\hline Previous & $96(32.4)$ & $95(32.1)$ & .007 \\
\hline Within $2 \mathrm{wk}$ & $50(16.9)$ & $50(16.9)$ & 0 \\
\hline NYHA class III/IV, n (\%) & $50(16.9)$ & $50(16.9)$ & .02 \\
\hline Peripheral vascular disease, $\mathrm{n}(\%)$ & $37(12.5)$ & $33(11.1)$ & .042 \\
\hline Coronary artery disease, $\mathrm{n}(\%)$ & $99(33.5)$ & $98(33.1)$ & .007 \\
\hline Family history, n (\%) & $18(6.1)$ & $13(4.4)$ & .077 \\
\hline \multicolumn{4}{|l|}{ Aortic valve, $\mathrm{n}(\%)$} \\
\hline Stenosis & $228(77.0)$ & $221(74.7)$ & .062 \\
\hline Insufficiency & $266(89.9)$ & $263(88.9)$ & .029 \\
\hline Endocarditis, n (\%) & $11(3.7)$ & $13(4.4)$ & .037 \\
\hline Creatinine, $\mathrm{mg} / \mathrm{dL}$, mean $\pm \mathrm{SD}$ & $1.07 \pm 0.67$ & $1.08 \pm 0.86$ & .007 \\
\hline Outcomes & & & $P$ value \\
\hline 30-d mortality, n (\%) & $6(2.0)$ & $11(3.7)$ & .0625 \\
\hline Permanent stroke, n (\%) & $3(3.0)$ & $4(3.1)$ & 1 \\
\hline
\end{tabular}

$A V R$, Aortic valve replacement; $S M D$, standardized mean difference; NYHA, New York Heart Association.

of $2.6 \%$ to $4.0 \%,{ }^{17}$ secondary to what we encountered. Using CT scanning to assess the anatomy may help determine the entry site, identify contraindications, and potentially diminish conversions. ${ }^{6}$ Despite this, we have not routinely obtained CT scans and have demonstrated low conversion and stroke rates.

The use of sutureless valves may ultimately improve the adoption rate of minimally invasive surgery, ${ }^{26}$ especially through a right thoracotomy approach. Miceli and colleagues $^{27}$ demonstrated outstanding results with a minithoracotomy sutureless AVR approach, showing a $40 \%$ reduction in perfusion and clamp times.

In a real-world, propensity-matched study, Muneretto and colleagues ${ }^{28}$ demonstrated significantly higher 30-day mortality rates with transcatheter aortic valve replacement (TAVR) compared with surgical aortic valve replacement (SAVR) or sutureless AVR, as well as fewer adverse events and paravalvular regurgitation with the latter 2 approaches. Another propensity-matched study revealed a trend toward improved early and mid-term results with sutureless valves compared with TAVR. ${ }^{29}$ In contrast, several studies have documented improved results with TAVR compared with SAVR in intermediate-risk groups and have suggested that TAVR may be the preferred treatment alternative in such groups. In addition, a recent randomized trial (PARTNER
2, cohort A) demonstrated no significant difference in the rates of death or disabling stroke at 2 years between TAVR and surgery in an intermediate-risk group. ${ }^{27}$ The 30 -day mortality rates for TAVR and SAVR were 3.9\% and $4.1 \%$, respectively, and the stroke rates were $5.5 \%$ and $6.1 \%$, respectively. Despite this, there have been no randomized trials comparing any minimally invasive approach with or without a sutureless valve with TAVR. Hypothetically, a minimally invasive minithoracotomy approach with a sutureless valve may be the real-world alternative procedure to TAVR in intermediate-risk or even high-risk patients. ${ }^{30,31}$

We have demonstrated the feasibility and excellent results in concomitant cases with a minithoracotomy approach. Despite the heterogenicity of cases performed through a right thoracotomy (Table 2), the overall 30-day mortality rate was $3.2 \%$, and the reexploration rate was $2.1 \%$ (8 of 378). David and colleagues ${ }^{32}$ documented a $6.5 \%$ operative mortality rate in a group of 123 patients who underwent combined aortic root and mitral valve operations and a $15 \%$ reexploration rate for bleeding. Our low rate of reexploration can be attributed to the sternal-sparing approach used. In our younger age group, $40.3 \%$ of the patients did not receive a transfusion, compared with only $12.6 \%$ in the older group. This, along 
with the higher atrial fibrillation rates and longer ICU and hospital stays in the older age group, did not result in higher mortality rates $(3.2 \%$ vs $3.2 \%)$. The overall incidence of permanent stroke was higher in the older group $(2.1 \% \mathrm{vs}$ $0.7 \% ; P=.25$ ) and reached statistical significance in those who underwent femoral cannulation $(2.5 \%$ vs $0.0 \%$; $P=.010)$. This may be attributed to differences in the atherosclerotic burden (such as in those patients with PVD) between the 2 age groups $(9.5 \%$ vs $16.8 \%$; $P=.052$ ) (Table E2). Thournai and colleagues ${ }^{33}$ analyzed 23,404 patients from the STS database who underwent concomitant AVR and mitral valve replacement, and found an overall mortality rate of $10.0 \%$ and a neurologic complication rate of $5.5 \%$. The feasibility of performing concomitant AVR procedures also demonstrates an extended application of minithoracotomy approaches, but because they are more complex and technically challenging, these approaches should be approached with caution.

\section{Limitations}

This study's retrospective, observational, singleinstitution, single-surgeon (J.L.) design may limit its widespread generalizability. Furthermore, only the 30-day outcomes were assessed, and so the potential long-term benefits, which include survival, reoperation rate, patient prosthetic mismatch, long-term echocardiographic data, and functional improvement, were not determined. There was also significant heterogeneity among the patients because of the limited exclusion criteria; all risk groups were included, and the STS scores were not assessed individually. Paravalvular leakage rates were not systematically recorded, because we initially observed an extremely low incidence rate. In the concomitant group, we did not differentiate between whether a mitral valve repair or replacement was performed; these were grouped together as a mitral procedure. We did not compare the results of our technique against those achieved with traditional sternotomy-based aortic valve surgery, sutureless rapid-deployment aortic valve surgery, or TAVR.

Regarding the propensity score matching analysis, which was performed to adjust for relevant confounding variables within both groups, we were unable to include a few important preoperative variables because of missing data. Although we were unable to detect a statistically significant difference in 30-day death and postoperative cerebrovascular accident rates between isolated and concomitant AVR, the $P$ value approached significance, and it is possible that an effect could be shown with a larger sample size or by using additional preoperative variables that were not readily available. In addition, we were unable to evaluate the risk of greatly advanced age using a propensity score analysis, although we did observe low rates of 30-day mortality and other adverse outcomes in this older patient population, which is known to be at greater operative risk. We believe that the univariate comparisons of our isolated and concomitant repairs stratified by advanced age ( $<80$ years vs $\geq 80$ years) brings value to this report and adds to the sparse literature in this field.

\section{CONCLUSIONS}

Minimally invasive right minithoracotomy approaches to AVR are safe and have acceptably low complication and conversion rates. Patients age $\geq 80$ had a higher incidence of heart failure and a slightly higher 30-day mortality rate. They also received more transfusions and had more atrial fibrillations and longer ventilation times and ICU and hospital stays. In both groups, with or without femoral cannulation, the stroke rates were similar and were comparable to those reported previously for sternotomybased procedures.

Complex concomitant AVR procedures, even those requiring circulatory arrest, carry a higher risk than isolated AVR cases. Nonetheless, they can be safely performed with acceptable mortality and conversion rates in all age groups. Similar to our older patients with isolated AVRs, these patients had higher rates of transfusion and atrial fibrillation and longer ICU and hospital lengths of stay. The concomitant group age $\geq 80$ years had more PVD and higher stroke rates with femoral cannulation. Consideration should be given to performing routine $\mathrm{CT}$ angiography in this particular group.

Our study demonstrates that patients at low-tointermediate risk and selected high-risk patients should not be denied minimally invasive isolated or concomitant AVR surgery solely because of their chronological age without considering their biological age. Consideration should be given to adding minimally invasive aortic valve surgery as another subset in the new low-risk TAVR trials, although, owing to a lack of standardized techniques, results may vary.

\section{Conflict of Interest Statement}

Dr Lamelas receives honoraria from Medtronic, St Jude, and On-Q and has an ownership interest in Miami Instruments. All other authors have nothing to disclose with regard to commercial support.

\section{References}

1. Cosgrove DM III, Sabik JF. Minimally invasive approach for aortic valve operations. Ann Thorac Surg. 1996;62:596-7.

2. LaPietra A, Santana O, Pineda AM, Mihos CG, Lamelas J. Outcomes of aortic valve and concomitant ascending aorta replacement performed via a minimally invasive right thoracotomy approach. Innovations (Phila). 2014;9:339-42; discussion 342 .

3. Santana O, Reyna J, Grana R, Buendia M, Lamas GA, Lamelas J. Outcomes of minimally invasive valve surgery versus standard sternotomy in obese patients undergoing isolated valve surgery. Ann Thorac Surg. 2011;91:406-10.

4. Mihos CG, Santana O, Pineda AM, La Pietra A, Lamelas J. Aortic valve replacement and concomitant right coronary artery bypass grafting performed via a right minithoracotomy approach. Innovations (Phila). 2014;9:302-5. 
5. Glauber M, Gilmanov D, Farneti PA, Kallushi E, Miceli A, Chiaramonti F, et al Right anterior minithoracotomy for aortic valve replacement: 10-year experience of a single center. J Thorac Cardiovasc Surg. 2015;150:548-56.e2.

6. O'Brien SM, Shahian DM, Filardo G, Ferraris VA, Haan CK, Rich JB, et al. The Society of Thoracic Surgeons 2008 cardiac surgery risk models: part 2-isolated valve surgery. Ann Thorac Surg. 2009;88(1 Suppl):S23-42.

7. Lamelas J. Minimally invasive aortic valve replacement: the "Miami method" Ann Cardiothorac Surg. 2015;4:71-7.

8. LaPietra A, Santana O, Mihos CG, DeBeer S, Rosen GP, Lamas GA, et al Incidence of cerebrovascular accidents in patients undergoing minimally invasive valve surgery. J Thorac Cardiovasc Surg. 2014;148:156-60.

9. Thourani VH, Suri RM, Gunter RL, Sheng S, O'Brien SM, Ailawadi G, et al. Contemporary real-world outcomes of surgical aortic valve replacement in 141,905 low-risk, intermediate-risk, and high-risk patients. Ann Thorac Surg. 2015;99:55-61.

10. Agarwal S, Garg A, Parashar A, Svensson LG, Tuzcu EM, Navia JL, et al. In-hospital mortality and stroke after surgical aortic valve replacement: a nationwide perspective. J Thorac Cardiovasc Surg. 2015;150:571-8.e8.

11. Gilmanov D, Bevilacqua S, Murzi M, Cerillo AG, Gasbarri T, Kallushi E, et al Minimally invasive and conventional aortic valve replacement: a propensity score analysis. Ann Thorac Surg. 2013;96:837-43.

12. Lim JY, Deo SV, Altarabsheh SE, Jung SH, Erwin PJ, Markowitz AH, et al. Conventional versus minimally invasive aortic valve replacement: pooled analysis of propensity-matched data. J Card Surg. 2015;30:125-34.

13. Merk DR, Lehmann S, Holzhey DM, Dohmen P, Candolfi P, Misfeld M, et al. Minimal invasive aortic valve replacement surgery is associated with improved survival: a propensity-matched comparison. Eur J Cardiothorac Surg. 2015; 47:11-7; discussion 17.

14. Phan K, Xie A, Di Eusanio M, Yan TD. A meta-analysis of minimally invasive versus conventional sternotomy for aortic valve replacement. Ann Thorac Surg. 2014;98:1499-511.

15. Nicolini F, Agostinelli A, Fortuna D, Contini GA, Pacini D, Gabbieri D, et al. Outcomes of patients undergoing concomitant mitral and aortic valve surgery: results from an Italian regional cardiac surgery registry. Interact Cardiovasc Thorac Surg. 2014;19:763-70.

16. Nguyen TC, Lamelas J. From the ground up: building a minimally invasive aortic valve surgery program. Ann Cardiothorac Surg. 2015;4:178-81.

17. Brown ML, McKellar SH, Sundt TM, Schaff HV. Ministernotomy versus conventional sternotomy for aortic valve replacement: a systematic review and meta-analysis. J Thorac Cardiovasc Surg. 2009;137:670-9.e5.

18. Ghanta RK, Lapar DJ, Kern JA, Kron IL, Speir AM, Fonner E Jr, et al Minimally invasive aortic valve replacement provides equivalent outcomes at reduced cost compared with conventional aortic valve replacement: a real-world multi-institutional analysis. J Thorac Cardiovasc Surg. 2015;149: 1060-5.

19. Santana O, Pineda AM, Cortes-Bergoderi M, Mihos CG, Beohar N, Lamas GA, et al. Hybrid approach of percutaneous coronary intervention followed by minimally invasive valve operations. Ann Thorac Surg. 2014; 97:2049-55.

20. Miceli A, Murzi M, Gilmanov D, Fugá R, Ferrarini M, Solinas M, et al. Minimally invasive aortic valve replacement using right minithoracotomy is associated with better outcomes than ministernotomy. J Thorac Cardiovasc Surg. 2014;148:133-7.

21. Lamelas J, Sarria A, Santana O, Pineda AM, Lamas GA. Outcomes of minimally invasive valve surgery versus median sternotomy in patients age 75 years or greater. Ann Thorac Surg. 2011;91:79-84.

22. Gilmanov D, Farneti PA, Ferrarini M, Santarelli F, Murzi M, Miceli A, et al. Full sternotomy versus right anterior minithoracotomy for isolated aortic valve replacement in octogenarians: a propensity-matched study. Interact Cardiovasc Thorac Surg. 2015;20:732-41; discussion 741.

23. Schmitto JD, Mohr FW, Cohn LH. Minimally invasive aortic valve replacement: how does this perform in high-risk patients? Curr Opin Cardiol. 2011;26:118-22.

24. Santana O, Reyna J, Benjo AM, Lamas GA, Lamelas J. Outcomes of minimally invasive valve surgery in patients with chronic obstructive pulmonary disease. Eur J Cardiothorac Surg. 2012;42:648-52.

25. Murtuza B, Pepper JR, Stanbridge RD, Jones C, Rao C, Darzi A, et al. Minimal access aortic valve replacement: is it worth it? Ann Thorac Surg. 2008;85: 1121-31.

26. Borger MA, Moustafine V, Conradi L, Knosalla C, Richter M, Merk DR, et al. A randomized multicenter trial of minimally invasive rapid deployment versus conventional full sternotomy aortic valve replacement. Ann Thorac Surg. 2015; 99:17-25.

27. Miceli A, Gilmanov D, Murzi M, Marchi F, Ferrarini M, Cerillo AG, et al. Minimally invasive aortic valve replacement with a sutureless valve through a right anterior mini-thoracotomy versus transcatheter aortic valve implantation in high-risk patients. Eur J Cardiothorac Surg. 2016;49:960-5.

28. Muneretto C, Alfieri O, Cesana BM, Bisleri G, De Bonis M, Di Bartolomeo R, et al. A comparison of conventional surgery, transcatheter aortic valve replacement, and sutureless valves in "real-world" patients with aortic stenosis and intermediate- to high-risk profile. $J$ Thorac Cardiovasc Surg. 2015;150: 1570-7; discussion 1577-79.

29. Glauber M, Miceli A. Minimally invasive aortic valve replacement with sutureless valve is the appropriate treatment option for high-risk patients and the "real alternative" to transcatheter aortic valve implantation. J Thorac Cardiovasc Surg. 2016;151:610-3.

30. Leon MB, Smith CR, Mack MJ, Makkar RR, Svensson LG, Kodali SK, et al. Transcatheter or surgical aortic-valve replacement in intermediate-risk patients. N Engl J Med. 2016;374:1609-20.

31. Thourani VH, Kodali S, Makkar RR, Herrmann HC, Williams M, Babaliaros V, et al. Transcatheter aortic valve replacement versus surgical valve replacement in intermediate-risk patients: a propensity score analysis. Lancet. 2016;387: 2218-25.

32. David TE, Armstrong S, Maganti M, Ihlberg L. Clinical outcomes of combined aortic root replacement with mitral valve surgery. J Thorac Cardiovasc Surg. 2008; $136: 82-7$

33. Thourani VH, Suri RM, Rankin JS, He X, O'Brien SM, Badhwar V, et al. Does mitral valve repair offer an advantage over replacement in patients undergoing aortic valve replacement? Ann Thorac Surg. 2014;98:598-603; discussion 604.

Key Words: aortic valve replacement, open surgery, minimally invasive, outcomes 
TABLE E1. Preoperative characteristics of 1018 patients who underwent isolated minimally invasive aortic valve replacement, stratified by age

\begin{tabular}{|c|c|c|c|c|}
\hline Characteristic & Age $<80$ y $(n=705)$ & Age $\geq 80$ y $(n=313)$ & Total $(\mathrm{n}=1018)$ & $P$ value \\
\hline \multicolumn{5}{|l|}{ Age, $y$} \\
\hline Mean \pm SD & $67.4 \pm 10.7$ & $83.8 \pm 3.1$ & $72.5 \pm 11.8$ & $<.0001$ \\
\hline Range & $22.0-79.0$ & $80.0-94.0$ & $22.0-94.0$ & \\
\hline Male sex, $\mathrm{n}(\%)$ & $456(64.7)$ & $152(48.6)$ & $608(9.7)$ & $<.0001$ \\
\hline Diabetes mellitus, n (\%) & $225(31.9)$ & $73(23.3)$ & $298(29.3)$ & .005 \\
\hline \multicolumn{5}{|l|}{ Ejection fraction, $\mathrm{mL}$} \\
\hline No. of patients & 695 & 310 & 1005 & \\
\hline Mean $\pm \mathrm{SD}$ & $57.8 \pm 10.2$ & $57.7 \pm 10.3$ & $57.8 \pm 10.2$ & .85 \\
\hline Range & $15-78$ & $20-75$ & $15-78$ & \\
\hline Renal insufficiency, $\mathrm{n}(\%)^{*}$ & $47(6.7)$ & $33(10.5)$ & $80(7.9)$ & .034 \\
\hline Dialysis, n (\%) & $12 / 702(1.7)$ & $2(0.6)$ & $14 / 1015(1.4)$ & .18 \\
\hline Hypertension, n (\%) & $596(84.5)$ & $288(92.0)$ & $884(86.8)$ & .001 \\
\hline Chronic lung disease, $\mathrm{n}(\%)$ & $121(17.2)$ & $52(16.6)$ & $173(17.0)$ & .83 \\
\hline \multicolumn{5}{|l|}{ Heart failure, $\mathrm{n} / \mathrm{N}(\%)$} \\
\hline Previous & $146 / 697$ (20.9) & $100 / 308(32.5)$ & $246 / 1005(24.5)$ & $<.0001$ \\
\hline Within 2 wk & 71/684 (10.4) & $53 / 297(17.8)$ & $124 / 981(12.6)$ & .001 \\
\hline \multicolumn{5}{|l|}{ NYHA class, n (\%) } \\
\hline $\mathrm{I} / \mathrm{II}$ & $88(12.5)$ & $45(14.4)$ & $133(13.1)$ & .41 \\
\hline III/IV & $71(10.1)$ & $53(16.9)$ & $124(12.2)$ & .002 \\
\hline Peripheral vascular disease, $\mathrm{n}(\%)$ & $71(10.1)$ & $42(13.4)$ & $113(11.1)$ & .12 \\
\hline Family history of CAD, n/N (\%) & $43 / 662(6.5)$ & $15 / 289(5.2)$ & $58 / 951(6.1)$ & .44 \\
\hline \multicolumn{5}{|l|}{ Aortic valve, n/N (\%) } \\
\hline Stenosis & $614 / 693(88.6)$ & $309 / 311(99.4)$ & 923/1004 (91.9) & $<.0001$ \\
\hline Insufficiency & $581 / 660(88.0)$ & $259 / 296(87.5)$ & $840 / 956(87.9)$ & .82 \\
\hline Endocarditis, n (\%) & $16(2.3)$ & $1(0.3)$ & $17(1.7)$ & .025 \\
\hline \multicolumn{5}{|l|}{ Creatinine, $\mathrm{mg} / \mathrm{dL}$} \\
\hline Median (IQR) & $0.9(0.8-1.1)$ & $1.0(0.8-1.2)$ & $0.9(0.8-1.2)$ & .004 \\
\hline Range & $0.1-9.2$ & $0.3-3.6$ & $0.1-9.2$ & \\
\hline \multicolumn{5}{|l|}{ STS score } \\
\hline No. of patients & 628 & 282 & 910 & \\
\hline Mean \pm SD & $1.6 \pm 1.1$ & $3.8 \pm 2.0$ & $2.3 \pm 1.8$ & $<.0001$ \\
\hline Range & $0.4-8.3$ & $1.3-14.3$ & $0.4-14.3$ & \\
\hline
\end{tabular}

$S D$, Standard deviation; NYHA, New York Heart Association; $C A D$, coronary artery disease; IQR, interquartile range; STS, Society of Thoracic Surgeons. *Renal insufficiency defined as creatinine $>1.5 \mathrm{mg} / \mathrm{dL}$ 
TABLE E2. Preoperative characteristics of 378 patients who underwent concomitant minimally invasive aortic valve replacement, stratified by age

\begin{tabular}{|c|c|c|c|c|}
\hline Characteristic & Age $<80$ y $(n=283)$ & Age $\geq 80$ y $(n=95)$ & Total $(n=378)$ & $P$ value \\
\hline \multicolumn{5}{|l|}{ Age, y } \\
\hline Mean \pm SD & $66.7 \pm 11.0$ & $83.9 \pm 3.3$ & $71.0 \pm 12.2$ & $<.0001$ \\
\hline Range & $26.0-79.0$ & $80.0-97.0$ & $26.0-97.0$ & \\
\hline Male sex, n (\%) & $154(54.4)$ & $34(35.8)$ & $188(49.7)$ & .002 \\
\hline Diabetes mellitus, n (\%) & $73(25.8)$ & $31(32.6)$ & $104(27.5)$ & .20 \\
\hline \multicolumn{5}{|l|}{ Ejection fraction, $\mathrm{mL}$} \\
\hline No. of patients & 280 & 94 & 374 & \\
\hline Mean \pm SD & $56.0 \pm 11.8$ & $55.4 \pm 12.2$ & $55.9 \pm 11.8$ & .66 \\
\hline Range & $15.0-70.0$ & $23.0-70.0$ & $15.0-70.0$ & \\
\hline Renal insufficiency, $\mathrm{n}(\%)^{*}$ & $24(8.5)$ & $11(11.6)$ & $35(9.3)$ & .37 \\
\hline Dialysis, n (\%) & $12(4.3)$ & $1(1.1)$ & $13 / 377(3.4)$ & .14 \\
\hline Hypertension, n (\%) & $240 / 281(85.4)$ & $91(95.8)$ & $331 / 376(88.0)$ & .007 \\
\hline Chronic lung disease, $\mathrm{n}(\%)$ & $43(15.2)$ & $16(16.8)$ & $59(15.6)$ & .70 \\
\hline \multicolumn{5}{|l|}{ Heart failure, $\mathrm{n} / \mathrm{N}(\%)$} \\
\hline Previous & $87 / 279(31.2)$ & $36 / 93(38.7)$ & $123 / 372(33.1)$ & .18 \\
\hline Within 2 wk & $42 / 266(15.8)$ & $21 / 90(23.3)$ & $63 / 356(17.7)$ & .11 \\
\hline \multicolumn{5}{|l|}{ NYHA class, $n(\%)$} \\
\hline $\mathrm{I} / \mathrm{II}$ & $48(17.0)$ & $19(20.0)$ & $67(17.7)$ & .50 \\
\hline III/IV & $42(14.8)$ & $21(22.1)$ & $63(16.7)$ & .10 \\
\hline Peripheral vascular disease, n (\%) & $27(9.5)$ & $16(16.8)$ & 43 (11.4) & .052 \\
\hline Family history of CAD, n/N (\%) & $12 / 261(4.6)$ & $5 / 91(5.5)$ & $17 / 352(4.8)$ & .73 \\
\hline \multicolumn{5}{|l|}{ Aortic valve, $\mathrm{n} / \mathrm{N}(\%)$} \\
\hline Stenosis & $191 / 267(71.5)$ & 91/93 (97.8) & $282 / 360(78.3)$ & $<.0001$ \\
\hline Insufficiency & $262 / 279(93.9)$ & $73 / 90(81.1)$ & $335 / 369(90.8)$ & .0003 \\
\hline Endocarditis, n (\%) & $19(6.7)$ & $1(1.1)$ & $20(5.3)$ & .033 \\
\hline \multicolumn{5}{|l|}{ Creatinine level, mg/dL } \\
\hline Median (IQR) & $0.9(0.8-1.1)$ & $1.0(0.8-1.3)$ & $0.9(0.8-1.2)$ & .24 \\
\hline Range & $0.1-9.5$ & $0.5-3.6$ & $0.1-9.5$ & \\
\hline \multicolumn{5}{|l|}{ STS score } \\
\hline No. of patients & 14 & 6 & 20 & \\
\hline Mean \pm SD & $2.3 \pm 1.4$ & $4.9 \pm 1.9$ & $3.1 \pm 2.0$ & .003 \\
\hline Range & $0.9-6.6$ & $3.3-8.5$ & $0.9-8.5$ & \\
\hline
\end{tabular}

$S D$, Standard deviation; NYHA, New York Heart Association; CAD, coronary artery disease; IQR, interquartile range; STS, Society of Thoracic Surgeons. *Renal insufficiency defined as creatinine $>1.5 \mathrm{mg} / \mathrm{dL}$. 